of the ulnar shaft without radial fracture which are sustained when warding off a blow with a stick. In two of the Monteggia fractures this was the mechanism and in the third it was caused by a blow from the handle of a pipe-wrench. Owing to difficulties in language it was not easy to ascertain the exact position of the arm when the blow fell, but within the limits of interpretation the histories were as follows.

Case 1-Nyanja male adult, employed as a mine loco driver. He was struck on the left elbow during a fight. He states that he was struck with a stick about three inches in diameter and that he raised his arm to guard himself. There was a compound comminuted fracture of the upper third of the ulna. The head of the radius was dislocated forwards. A small wound lay directly over the fracture and communicated with the elbow joint.

Case 2-Lala male adult employed as underground rock-drill operator. He was struck on the left forearm by the handle of a pipe-wrench which spun round on a pipe and struck his arm from below. The position of the arm at the time of impact is not known accurately, but from his description it appeared to have been pronated. There was a compound fracture at the junction of the middle and upper thirds of the ulna and anterior dislocation of the head of radius. The small wound lay just over the ulnar fracture.

Case 3-Chewa male adult employed as a fitter's assistant. He was assaulted on his way home at night by a Nyachusa African. The weapon was a log of wood about nine inches in diameter and three feet long. He stated that the arm was held in pronation at the time of impact. There was a simple fracture of the ulna at the junction of the middle and upper thirds with dislocation of the radial head. There was bruising over the ulnar fracture.

In all three cases the dislocation was easily reduced and maintained by putting the arm in supination with the elbow flexed as far as possible consistent with good circulation of the hand. In Case 1 the comminution of the ulna was such that the fragments were wired together through the wound. The patient is making good progress. In none of the cases has treatment progressed far enough to assess results. These three cases show that even if the usual mechanism of an anterior Monteggia fracture is that of forced pronation, it certainly can result from direct violence.

Yours truly,

F. W. HANFORD.

\title{
TROCHANTERIC FRACTURES OF THE FEMUR
}

To the Editor,

From Mr E. Mervyn Evans, Swansea, Wales

Journal of Bone and Joint Surgery.

DEAR Sir,

The November 1951 issue of the British Volume contains an article by Mr J. C. Scott on the treatment of trochanteric fractures which I feel should not pass unchallenged. This fracture has been discussed at length in the recent British and American literature, but $\mathrm{Mr}$ Scott is apparently of the opinion that the subject has not been faithfully covered and that the conclusions arrived at are unreliable, though he quotes no actual references in his paper. Among his opening sentences, for instance, is the following: "In the treatment of trochanteric fractures there must surely be definite indications for conservative or operative treatment, yet up to now there seems to have been little serious attempt to assess these indications." Surely the detailed reporting of 101 consecutive cases treated conservatively, and a further 110 similar cases treated by operation is not to be so lightly disregarded (Evans, E. M., Journal of Bone and Joint Surgery, 31-B, 190, 1949; and 33-B, 192, 1951).

vol. 34 B, No. 2, MAY 1952 
Later, he implies that operation is reserved for those with the best chance of survival, and refers to the term, " hospital mortality rate," as if in all the operative series reported only deaths in hospital were counted. I feel I must make clear once again that in the two Birmingham series the greatest care was taken to avoid the risk of any such criticism as this. The series of 110 cases treated by operation was strictly unselected, as the average age of $\mathbf{7 4 \cdot 3}$ implies. The series was consecutive, and during the period concerned every patient who was diagnosed in the admission department as having a trochanteric fracture was submitted to operation. Many were in poor shape, but it was felt that the worse their general condition the more urgent was the need for operation; the results achieved fully justified this belief; there were twelve deaths from all causes in the first five months, a mortality rate of $\mathbf{1 0 \cdot 9}$ per cent.

Turning to Mr Scott's own cases, he reports a series of fifty-four cases treated alternately by traction and internal fixation, and records the mortality rates of $\mathbf{2 8 . 6}$ per cent and 37 per cent respectively-and these figures are based on a follow-up period of three months, as opposed to our period of five months. The number of cases concerned is, as $\mathrm{Mr}$ Scott says, too small for statistical analysis, but the mortality figures do seem rather high, and in particular the figure of seven deaths from bronchopneumonia in twenty-seven cases operated on (26 per cent) surprises me. May I, therefore, set out once again the principles which I believe to govern the successful treatment of this fracture?

1. The fracture occurs for the most part in the aged, for whom swift relief of pain and early mobility are essential. The fracture itself is of secondary importance: firm fixation of the neck fragment to the shaft is the only essential, and accurate reduction is a luxury which must take second place in any patient over the age of seventy. Mr Scott himself implies this when he says that "sound union of a fracture in perfect position ... is of little value in a patient who is unable to walk for other reasons."

2. Early operation is most desirable, preferably within forty-eight hours of the injury. Equally important is early mobility, and almost all our patients were got out of bed within forty-eight hours of operation. Many fractures (20 per cent) are sufficiently stable after nailing to permit immediate weight-bearing; even in the unstable types early weight-bearing should be allowed if the general condition demands it, for coxa vara deformity is a small price to pay for survival.

3. We believe the type of anaesthetic used to be of great importance. Pentothal in small doses after efficient pre-medication, followed by gas and oxygen, would seem to be the most satisfactory. Equally important is the use of tracheal aspiration through an endotracheal tube at the end of the operation, and, if necessary, on the following day. In our series of 110 cases only two developed pneumonia, one before and one after operation; both patients recovered.

The mortality rate is, of course, not the only criterion to be considered. The degree of functional recovery to be expected must be taken into account, though in a group of patients whose average age is so high accurate assessment is difficult. In our cases treated by operation $\mathbf{9 0} \cdot \mathbf{8}$ per cent of the survivors were restored to their pre-accident activity, a figure which at least may be said to compare favourably with the results of any conservative series reported. There are other factors: operative treatment, as $\mathrm{Mr}$ Scott says, implies a pleasanter convalescence, and I have no doubt from personal experience effects a great saving in hospital keds. On all counts I believe routine operative treatment to be the method of choice, at any rate in the aged. We in Birmingham have made a " serious attempt to assess the indications," and I assure you, Sir, have been most careful to ensure that our published results are not "fallacious."

Yours truly,

January 23,1952 .

E. M. EVANS.

THE JOCRNAL OF BONE AND JOINT SURGERY 